\title{
The Popularization of Specialized Knowledge Through Ted Talks: The Case of Positive Psychology
}

\author{
Francesco Pierini ${ }^{1}$ \\ ${ }^{1}$ Department of Political Science, University of Genoa, Italy \\ Correspondence: Francesco Pierini, Department of Political Science, University of Genoa, Italy. E-mail: \\ francesco.pierini@unige.it
}

Received: February 1, 2019

Accepted: March 20, 2019 Online Published: June 12, 2019

doi:10.5539/ijel.v9n4p15

\author{
URL: https://doi.org/10.5539/ijel.v9n4p15
}

\begin{abstract}
TED is a non-profit global platform where conferences and speeches — brief but powerful — are held by people who, based on the TED's motto, have an idea considered to be worth spreading. TED is often regarded as one of the best examples of positive globalization in its activity of knowledge-sharing and it defines itself as "a global community welcoming people from every discipline and culture who seek a deeper understanding of the world" (Note 1).

As Heller (2012) said, TED's talks are "sophisticated, popular, lucrative, socially conscious, and wildly pervasive - the Holy Grail of digital-age production". However, in some recent newspaper articles TED's approach to the dissemination of science has been criticized because considered simplistic, trivial and even biased (Bratton, 2013; Robbins, 2012). Notwithstanding, current studies in TED's approach to scientific popularisation show that science is directly brought into contact with people, without any mediation (Scotto di Carlo, 2014a).

The aim of this paper is to examine how a discipline such as positive psychology is represented in some successful speeches delivered by specialists at TED events. I will focus on the main linguistic and extra-linguistic strategies - such as non-verbal elements - used by experts and academics to convey specialized knowledge to lay people by using the main tools offered by discourse analysis. This will help to clarify whether this process of knowledge-dissemination established by this hybrid genre, is an effective mode of construing, representing and transmitting scientific information.
\end{abstract}

Keywords: popularization, TED, positive, psychology, dissemination

\section{Some Introductory Information about TED}

As the site shows, TED is a non-profit making organization whose acronym means Technology, Entertainment and Design, and through which, conferences and speeches(Note 2) are delivered by people who have an idea considered to be "worth spreading" (Note 3). Based in Vancouver, it was founded in 1984 and though at first TED focused on specific subjects, with the passing of time it started to deal with a wider range of topics that are listed alphabetically on its website. As TED grew, it widened its activity and operative modalities, no longer based exclusively on conferences and talks but also on education (TED-Ed) and support to projects. TED Prize(Note 4) is, for instance, an award given to "a leader with a fresh, bold vision for sparking global change"(Note 5), an event where $\$ 1,000,000$ are at stake to boost best thinkers.

The original TED conference takes place annually in North America, but it is now present all over the world, especially in Europe and Asia, thanks to independently organized events called TEDx, each of which can be watched freely on the TED website with a system of automatically generated subtitles in most languages and available for reading thanks to transcripts. It is also noteworthy that TED has been gaining weight in English Language Teaching (ELT). More and more teachers all over the world use TED talks in class and develop conference-related activities to teach English innovatively(Note 6).

\section{Aims and Scope of the Article}

After this short introduction to what TED is and how it works, I will concentrate my attention on a specific branch of science - positive psychology — in order to see how this discipline has been dealt with by scholars in TED talks, and consequently comprehend how scientific concepts and theories can be been conveyed by experts to common 
people in an unusual context. The choice of positive psychology is mainly due to the persuasive models that are typical of what has come to be recognized as a 'best practice', a model of successful presentation, the TED's style.

Tedsters - as speakers at the conference are also called - are generally regarded as gurus and their speeches are based on the art of effective public speaking; persuasion is one of the main ingredients used by presenters in order to spark off change. TED speakers perform on a stage, before a big audience and are visible online by millions of spectators, therefore they must skilfully manage both verbal and nonverbal communication, besides possessing great expertise. Thus, the questions underlying this research are two: 1) How is specialized knowledge conveyed to lay people through TED? And 2) What persuasive devices do Tedsters use to be successful?

\section{Methodology of Research}

In order to examine how positive psychology is discursively represented and conveyed to a lay public through TED I will resort to Discourse Analysis (DA) as a theoretical framework and I will make use of text mining in order to get relevant data. Harris regarded DA as a way "to examine language beyond the level of the sentence and the relationship between linguistic and non-linguistic behavior" (quoted in Paltridge, 2006, p. 2). For my study I used some online software programs - Textalyser.net and Analyzemywriting.com - two text analysis tools which allow obtaining a lot of useful statistical data about texts such as verbal elements (word frequency, word/sentence length, lexical density and readability) as well as nonverbal features (applause, laughter, speaking pace). These aspects can significantly help understand how the scholar represents science when s/he conveys it to people lacking specialist knowledge.

In order to understand how positive psychology is represented in TED Talks and see how knowledge is conveyed from the scientific community to a vaster audience I will briefly introduce what this branch of science deals with. Peterson defines positive psychology as "what makes life most worth living" (2006, p. 4). This area of study originated in the late 1990s with Seligman who stated that "for the last half century psychology has been consumed with a single topic only-mental illness" (2002, p. xi). Though several studies on positive psychology have witnessed improvement in well-being and depression, there has been no lack of discussion and controversy on this branch of knowledge. Partly it is due to the origin and ceaseless propagation of non- or pseudoscientific disciplines such as coaching and further developments of Neuro-Linguistic Programming, which are still refuted by the scientific community, so that psychology itself may have been affected by this disregard.

\section{Public Speaking}

TED Talks and public speaking go together; the latter has become one of the most appreciated and necessary skills in our age. Research estimates that "by the year 2020 knowledge [...] in the world will double every seventy-three days" (Edmund, 2005, p. 13) since it "[...] is said to be our greatest industry"(ibid.). Therefore, due to the big exchange of content, communicating in a way that is accessible to others is more important today than ever before. TED blends the three main purposes of public speaking - to inform, persuade or entertain an audience (Coopman\& Lull, 2012), so, in most cases the speeches delivered can be informative, persuasive and entertaining at the same time. They may often intermingle, though since TED's motto is based on 'ideas worth spreading', Tedsters necessarily have to convince the spectator. As Gass and Seiter state,

scientists must do more than conduct experiments and report their results. They also must persuade other scientists, funding agencies, and the public at large of the merits of their work (Gass\&Seiter, 2015, p. 238).

Persuasion is a complex art/science and "human communication [is] designed to influence the autonomous judgments and actions of others" (Simons, 2001, p. 7) and consequently it is "a form of attempted influence in the sense that it seeks to alter the way others think, feel, or act" (ibid.).

\subsection{Effective Public Speaking: From Classical Rhetoric to Our Digital Age}

The art of public speaking started in ancient times and there is evidence that some training in the field was made in ancient Egypt, though it was the Greeks who really kicked off interest and research into this area. They developed the main principles from the activity and skills used by orators and through rhetoric — the main ingredient — this art was passed on to the Romans who developed models and tenets that are still the foundations of modern public speaking. Though the basics of public speaking have not changed so much since classical times, as Coopman and Lull state in the title of their book this is an "evolving art" (2012), thus the ways you prepare and deliver a good speech or presentation have changed a lot, if only for the development of communication techniques by means of technology.

The Latin style was the primary form of oration in the world until the beginning of the 20th century but after World War II, a gradual deprecation of this style of speech delivery began. With the rise of the scientific method and the emphasis on a "plain" style of speaking and writing, even formal oratory has become less polished and ornate than 
in the Classical period, though in some spheres of life, e.g., in politics, politicians can still make or break their careers on the basis of a successful (or unsuccessful) speech (Gregory, 2010).

The first modern scholar in the field was Dale Carnegie, who at the beginning of the XX century published the first mass-market public speaking and self-help book, whose intuition was flawless. He was a pioneer in his outlining some of the principles that are still valid nowadays after a century from the publication of his long-seller The Art of Public Speaking(Note 7). Among his advice he suggested short speeches, powerful stories to build empathy with the audience, rhetorical devices and the use of visual aids. As Gallo outlines TED is "Dale Carnegie for the twenty-first century [and] everything Carnegie suggested in 1915 remains the foundation of effective communication to this day" (Gallo, 2014, pp. 6-7).

One-to-many communication may be a very challenging activity and research into this branch of science has greatly increased since the beginnings of the 1950s. And though public speaking has become increasingly common in our world, glossophobia isn't at all a rare social anxiety disorder. As regards public speaking anxiety, studies started to focus on communication apprehension (CA), defined as "a broadly based anxiety related to oral communication" (McCroskey, 1970, p. 270) and later redefined by McCroskey himself as "an individual's level of fear or anxiety associated with either real or anticipated communication with another person or persons" (McCroskey, 1977, p. 78). Later on, McCroskey (1984) stated that 30 to $40 \%$ of American people are hit by CA to such an extent that their propensity and eagerness to speak in public is seriously impaired.

\subsection{Literature on TED}

TED is considered by most people as one of the best examples of positive globalization in its activity of knowledge dissemination and it defines itself as "a global community welcoming people from every discipline and culture who seek a deeper understanding of the world"(Note 8). However, some criticisms have started to arise since TED is also considered as a simplistic way to popularize scientific content. As behavioural scientist Schwartz-a defender of the TED model — said in an interview,

[...] it seems that the more pervasive TED's influence becomes, the more people criticize it. What are the criticisms? The talks oversimplify complex ideas. There is too much emphasis on performance, and not enough on substance. There seems to be a Panglossian attitude that anything that's new is good. It's too preachy, exhorting people of privilege and talent to ask themselves what they can do to make the world better, and by implication, downgrading those intellectual achievements that don't have a good answer to this question(Note 9).

TED's fame as a point of reference for effective public speaking is undisputed and some educational books published in the last few years are a clear evidence of it. Like many self-help manuals, they teach how to give a successful presentation by focusing on TED's most emblematic examples(Note 10). Indeed, a lot has been written on public speaking in the last decades because this skill has become increasingly important in contemporary society, but most texts about this subject have a very pragmatic approach and are structured as how-to manuals for self-improvement or at best as textbooks for courses dealing with sales, corporate training and communication.

In a debate that has arisen in recent years on the TED phenomenon, even at an academic level, there are supporters and opponents. Among the objectors, sociologist Bratton regards TED as "a recipe for civilisational disaster" and defines it as "middlebrow, megachurch infotainment" (2013). Also, researcher Robbins expresses a negative idea by stating that,

TED Talks are designed to make people feel good about themselves; to flatter them and make them feel clever and knowledgeable; to give them the impression that they're part of an elite group making the world a better place (2012).

Even Jurgenson, by referring to Steve Job's inimitable talk about life said that,

[w]hat began as something spontaneous and unique has today become a parody of itself. What was exceptional and emergent in the realm of ideas has been bottled, packaged, and sold back to us over and over again. The whole TED vibe has come to resemble a sales pitch (2012)(Note 11).

Over the last few years numerous publications have been devoted to TED, studying this genre of popularization discourse (Caliendo, 2012; Compagnone, 2017; D’Avanzo, 2015; Ludewig, 2017; Rasulo, 2015, 2018; Takaesu, 2013; Masi, 2016). Scotto Di Carlo has widely examined the TED experience from different angles - knowledge dissemination (2014), the use of figurative language (2014a), the role of humor (2014b), and her research shows that through TED, science is directly brought into contact with people by changing the typical and consolidated approach to scientific dissemination: from triangularization — scientist-mediator-audience - it has turned into a direct scientist-audience relationship. 
After all TED multimodality makes it a new genre which differs from the typical ways we have been used to in knowledge popularization, wittily defined by Caliendo as a "new hybrid genre" (2012, p. 101). Therefore, though specialized knowledge refers to domain-specific forms of academic and scientific facts, and makes use of highly specialized language, formal register and specific nomenclature, the way it is conveyed to the general public has changed. According to Sager et al. (1980, p. 323), the main features of 'traditional' scientific discourse are: a) mono-referentiality (conciseness and semantic uniqueness), b) an informative purpose (with no aesthetic or emotive elements) and c) some strict text structure rules (economy, accuracy and appropriateness); in TED talks these elements seem to have been replaced not only by a simplified form of language, but also a renewed delivery style which bring the public closer to the scientist.

From the point of view of scientific dissemination, some scholars have elaborated a model of communication based on a vertical framework. Specifically, Cloitre and Shinn (1985) identify four communication levels - they set up the connection between the participants in the communication process-which make TED appear as a sender-receiver oriented model. The four levels of specificity are not categories per se since they are conceived as a continuum:

\author{
Intra-specialist level \\ Inter-specialist level \\ Pedagogical level \\ Popular level \\ (Cloitre \& Shinn, 1985, pp. 31-60, passim)
}

The classification ranges from expert speakers (intra-specialists), who use the same language and terminology in interaction with each other, to a second level where we find people who make use of simplified language forms and concepts for specialists communicating across fields. The third group of speakers is represented by a public that has not mastered this language yet (e.g., students), and the fourth level of communication corresponds to the most accessible and popular one which takes place when specialists communicate with non-specialists.

Fahnestock (1986) maintains that there is a process of accommodating results and discussions of scientific investigation targeted to different audiences and outlines how scientific knowledge is conveyed from expert to non-expert audiences. In fact, she assumes that "scientific accommodations are overwhelmingly epideictic; their main purpose is to celebrate rather than validate (ibid., 1993, p. 19). There is also a rhetorical presentation of the results of the research which avoids the alienation of an unscientific public.

This could correspond to what TED talks are and do, through "their own authors using several discursive conventions to negotiate their role as experts and to establish a closer relationship with their audience" (Scotto di Carlo, 2014c, p. 591).

\title{
5. Analysis
}

\subsection{Context: TED}

Given that context plays a crucial role in DA, it is necessary to contextualize TED talks in order to better understand how the popularization of science takes place and to this end the main elements that we should take into consideration are the following:

1) Popularization has changed in the digital age

2) TED Talks are intended for knowledge-sharing (and popularization)

3) TED's success is evident (from live audience and remote audience)

4) TED Talks are considered models of public speaking (Talk like TED and other how to manuals)

5) Positive psychology as a science resembles many topics dealt with by other disciplines at TED

\subsection{Context: Speakers and Talks}

In this study four TED Talks were examined. The authors and related talks chosen for the analysis are Shawn Achor, a previous researcher at Harvard, now author and speaker; Dan Gilbert, professor of Psychology at Harvard; Mihaly Csikszentmihalyi, who is professor of Psychology and Management at Claremont Graduate University, and Martin Seligman, the founder of positive psychology and Professor of Psychology in the University of Pennsylvania. 


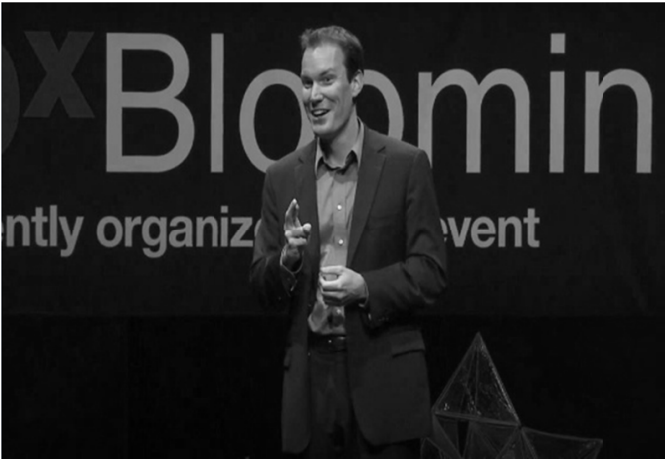

Shawn Achor

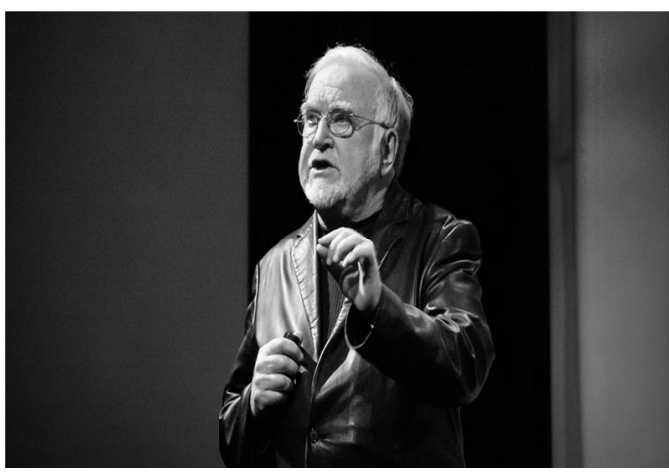

Mihaly Csikszentmihalyi

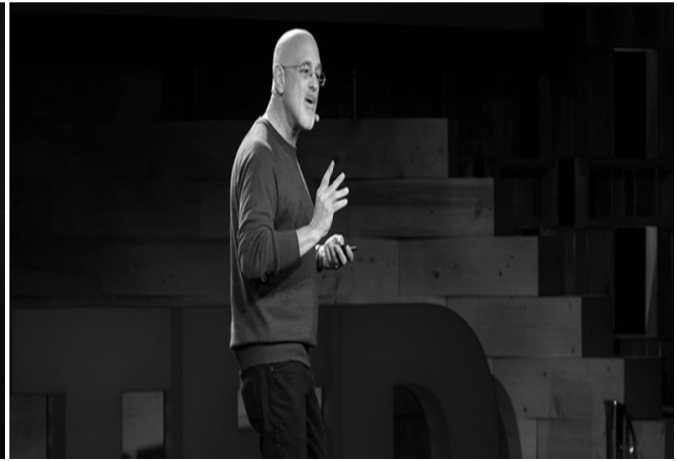

Dan Gilbert

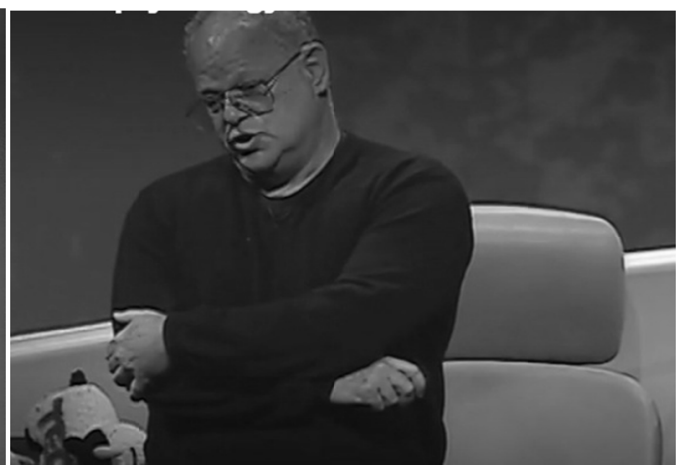

Martin Seligman

Note. www.ted.com.

In Table 1 some preliminary information about the authors and their talks are provided for the purpose of giving both more context for the analysis and to position the speakers socially and professionally.

One of the four talks is a TEDx (Bloomington), an independently organized meeting, whereas the other three are official TED events. Achor's talk was delivered in 2011 and the others date back to 2004. What we see is that all the speakers have a website but while Achor's has a commercial purpose, Gilbert, Csikszentmihalyi and Seligman have not. The last two are rather academic websites.

All four speeches have been successful on the TED platform, but from the number of viewers each of them has had so far, we see that Achor's and Gilbert's speeches have been clicked much more than those by Csikszentmihalyi and Seligman.

Table 1. Preliminary information about the speakers

\begin{tabular}{|c|c|c|c|c|}
\hline Items/Talks & $\begin{array}{l}\text { The happy secret to } \\
\text { better work } \\
\text { S. Achor } \\
\end{array}$ & $\begin{array}{l}\text { The surprising science of } \\
\text { happiness } \\
\text { D. Gilbert }\end{array}$ & $\begin{array}{l}\text { Flow, the secret to } \\
\text { happiness } \\
\text { M. Csikszentmihalyi } \\
\end{array}$ & $\begin{array}{l}\text { The new era of positive } \\
\text { psychology } \\
\text { M. Seligman }\end{array}$ \\
\hline \multirow[t]{2}{*}{ Year and place } & May 2011 & February 2004 & February 2004 & February 2004 \\
\hline & TEDxBloomington & TED2004 & TED2004 & TED2004 \\
\hline Views(Note 12) & $19,146,046$ & $16,567,411$ & $4,924,212$ & $4,874,785$ \\
\hline Website & Yes - commercial & Yes - non commercial & Yes - non commercial & Yes - non commercial \\
\hline
\end{tabular}

Note. https://www.ted.com/

\subsection{Vocal Elements of the Talks}

Table 2 illustrates the duration of the speech both in absolute and relative terms. As shown by the data the number of words used by Achor and Csikszentmihalyi is quite similar, whereas Gilbert's and Seligman's contributions are substantially longer - they exceed the 18-minute time frame usually granted to Tedsters - and it turns out that this also impinges on the estimated speaking time, considerably different for each presenter. In fact, the time used by the speakers highlights that vocal elements do play an important part since Achor utters his speech before the 
estimated time of speaking, Gilbert uses a little more than the time than expected, Csikszentmihalyi and Seligman both exceed the scheduled time(Note 13). This is further confirmed by the number of words spoken per minute which demonstrates that Achor's pace is faster and uninterrupted, Gilbert's is a bit more relaxed, whereas Csikszentmihalyi's and Seligman's are definitely slow-more typically in line with the models of scientific dissemination.

Table 2. Vocal elements of the talks

\begin{tabular}{|c|c|c|c|c|}
\hline Items/Talks & $\begin{array}{l}\text { The happy secret to } \\
\text { better work } \\
\text { S. Achor }\end{array}$ & $\begin{array}{l}\text { The surprising } \\
\text { science of happiness } \\
\text { D. Gilbert }\end{array}$ & $\begin{array}{l}\text { Flow, the secret to } \\
\text { happiness } \\
\text { M. Csikszentmihalyi }\end{array}$ & $\begin{array}{l}\text { The new era of } \\
\text { positive psychology } \\
\text { M. Seligman }\end{array}$ \\
\hline Words & 2,510 & 3,699 & 2,328 & 3,250 \\
\hline Estimated Speaking Time & $13: 56$ & $20: 33$ & $12: 56$ & 18:04 \\
\hline Speaking Time & $12: 20$ & $21: 16$ & $18: 55$ & $23: 35$ \\
\hline Words per minute & 206 & 175 & 125 & 139 \\
\hline
\end{tabular}

Note. https://wordcounter.net/

\subsection{Level of Complexity of the Talks}

Table 3 illustrates the level of complexity of the talks by focusing on various data. Complexity is meant as the combination of some indexes, such as the Gunning Fog index (an estimation of the readability of a text based on the years of schooling needed to understand it), the lexical density (the ratio between content words and grammar words), word lengths and sentence lengths. Though the lexical density seems to be on a very similar level for the four texts (just above 45\%) - thus hardly exceeding the typical values of spoken language(Note 14) - more information is provided by the Gunning Fog Index, which makes it clear that Csikszentmihalyi's talk is the most difficult of the four texts, since 13.2 corresponds to the level of schooling of a college freshman and Gilbert's talk is the easiest since 9.3 refers to a high school freshman/sophomore(Note 15).

Table 3. Level of complexity of the talks (a)

\begin{tabular}{lllll}
\hline Items/Talks & $\begin{array}{l}\text { The happy secret to } \\
\text { better work }\end{array}$ & $\begin{array}{l}\text { The surprising science of } \\
\text { happiness }\end{array}$ & $\begin{array}{l}\text { Flow, the secret to } \\
\text { happiness }\end{array}$ & $\begin{array}{l}\text { The new era of } \\
\text { positive psychology }\end{array}$ \\
\hline Gunning Fog Index & 11.8 & 9.3 & 13.2 & 11.2 \\
Lexical density & $47.4 \%$ & $46.7 \%$ & $45.1 \%$ & 48.1 \\
\hline
\end{tabular}

Note. http://www.analyzemywriting.com/

Table 4 examines word length from which no significant result emerges. In fact, the word length distribution is not noticeably different in any of the four speeches. The four talks have the same median length (4 words) and the average length is identical in both Achor's and Csikszentmihalyi's talks (4.43). The trend reaches its peak with 4-letter words in every speech and gradually declines in virtually the same way.

Table 4. Level of complexity of the talks (b)

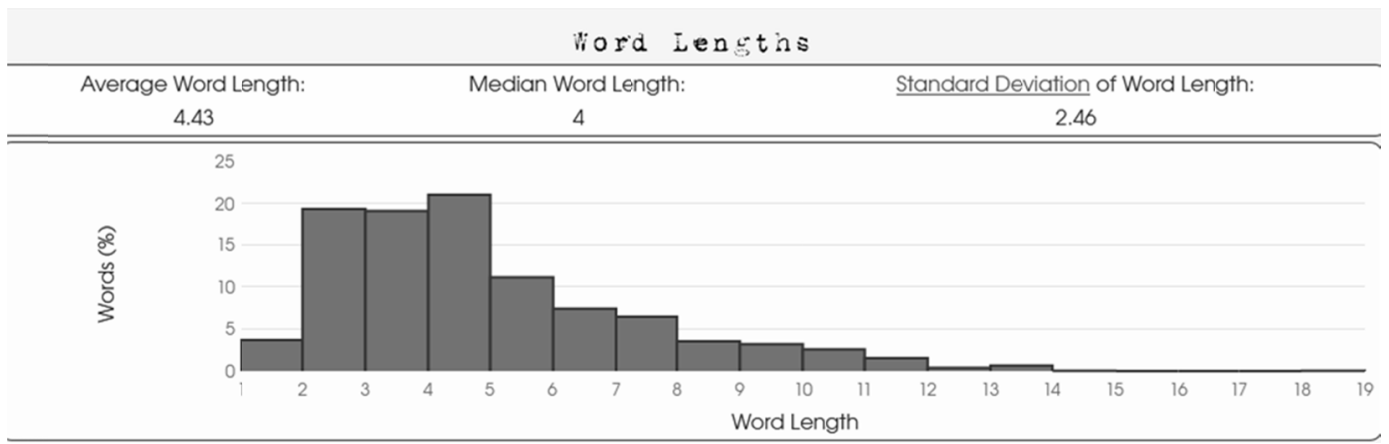

The happy secret to better work-S. Achor 


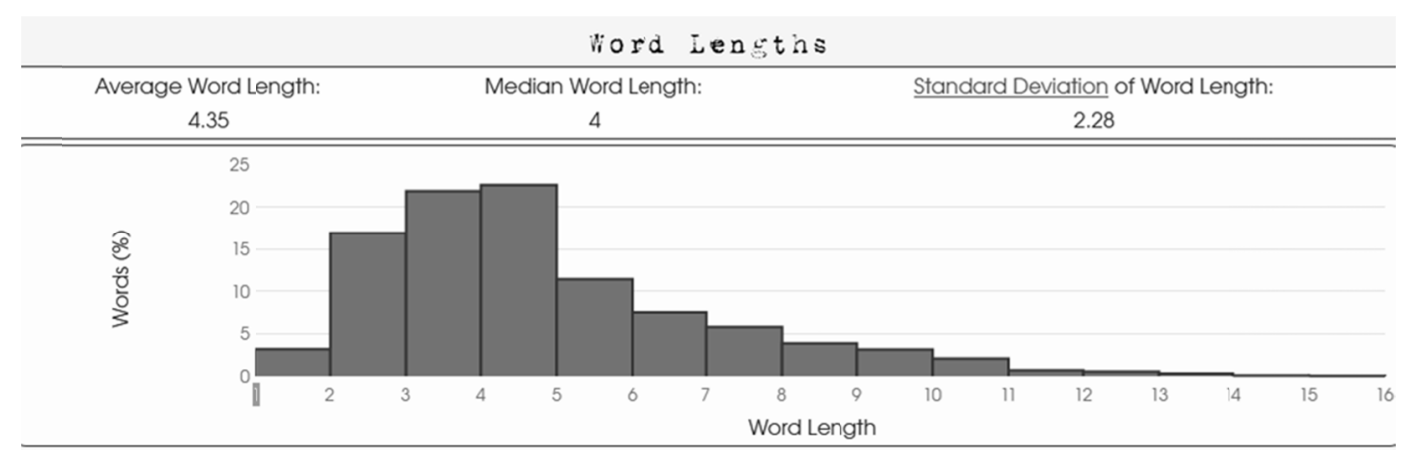

The surprising science of happiness-D. Gilbert

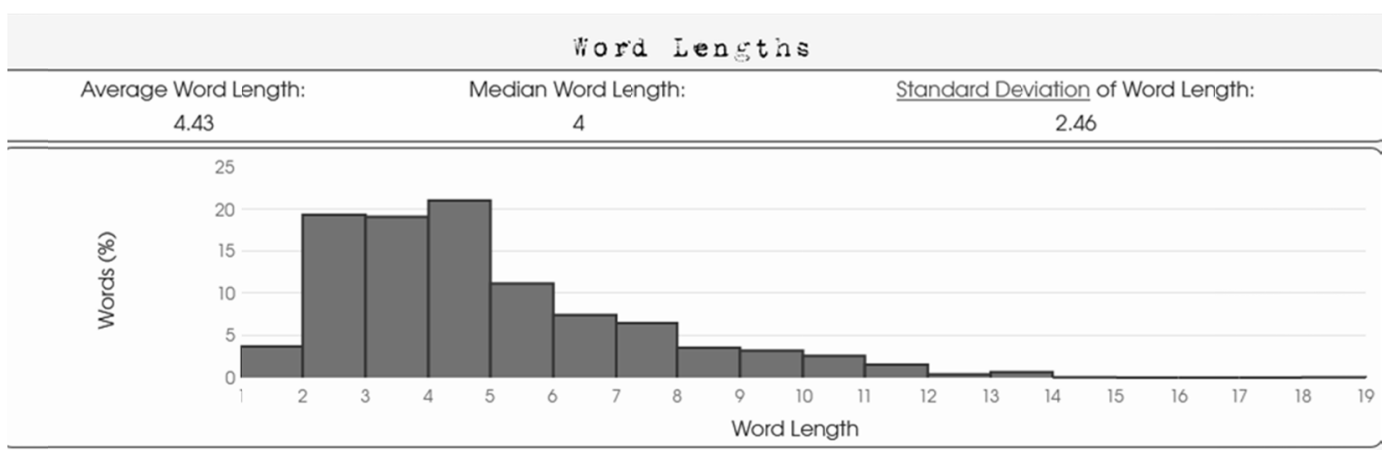

Flow, the secret to happiness-M. Csikszentmihalyi

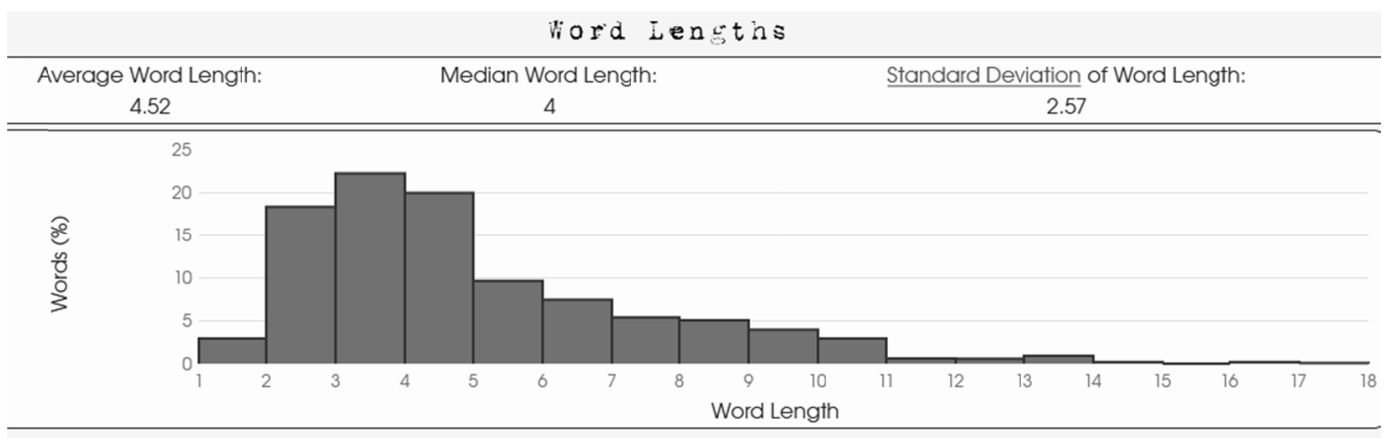

The new era of positive psychology—M. Seligman

Note. http://www.analyzemywriting.com/

Table 5 shows the lengths of sentences of the four talks. We may notice that Gilbert's units are less "spread out" than the other three, making it supposedly easier to understand. Achor's median sentence lengths amounts to 17 , Gilbert's to 10 and Seligman's to 13 words and their average sentence lengths to $19.43,13.74$ and 15.69 words. Therefore, Csikszentmihalyi's talk seems to be more complex because both median and average sentence lengths are longer (19 and 22.01). 
Table 5. Level of complexity of the talks: sentence lengths

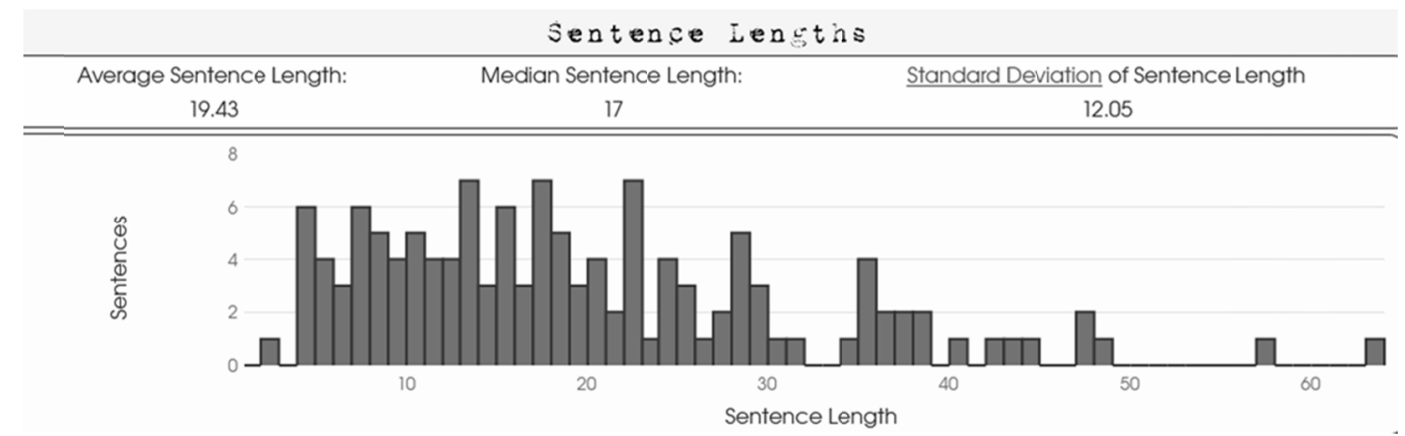

The happy secret to better work-S. Achor

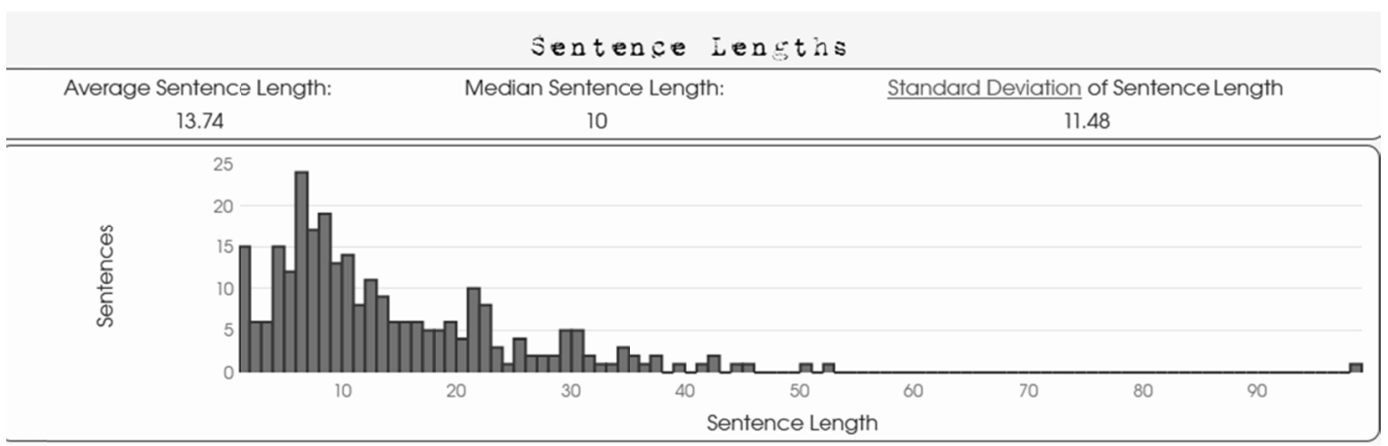

The surprising science of happiness-D. Gilbert

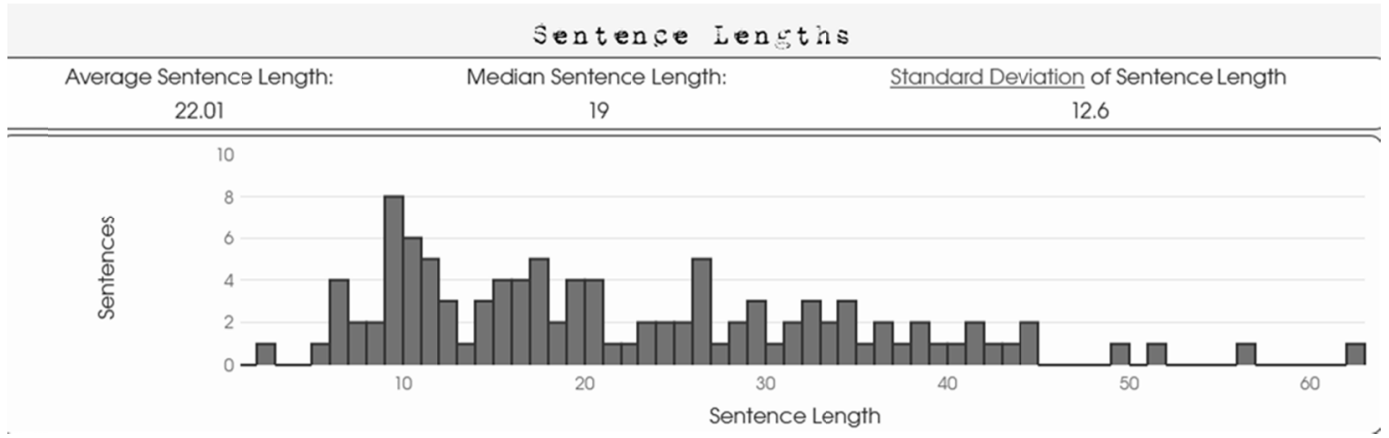

Flow, the secret to happiness-M. Csikszentmihalyi

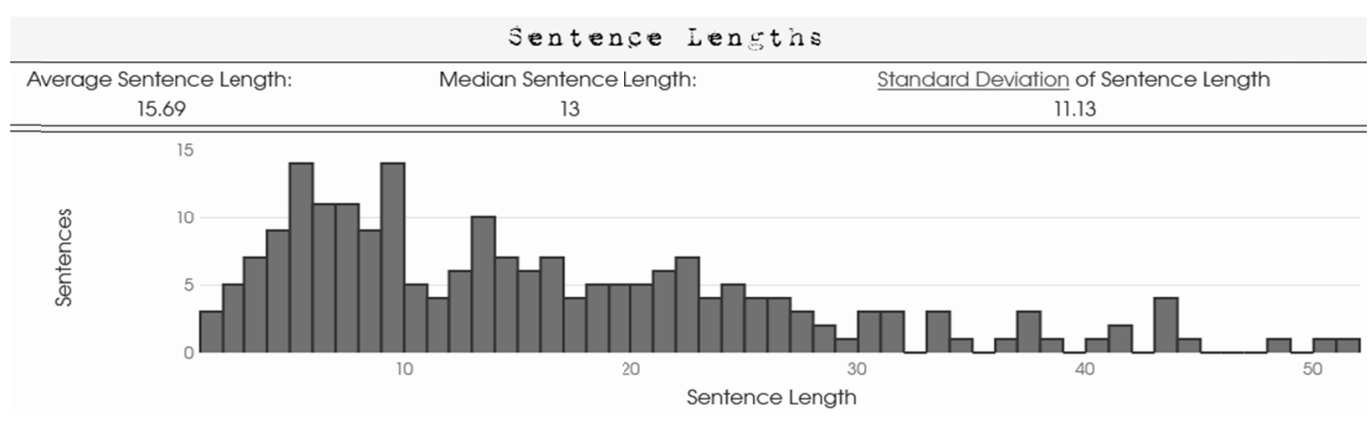

The new era of positive psychology—M. Seligman

Note. http://www.analyzemywriting.com/

\subsection{Lexical Features}

Table 6 illustrates some relevant information about word occurrences starting from the titles themselves. It can be seen that key words like "happy" and "happiness" occur in three titles matched to adjectives such as "secret" and "surprising", lending the speeches an idea of mystery and revelation that creates expectation and suspense. Only Seligman's speech clearly mentions the name of the science, positive psychology. In the wordlists provided 
"happiness" occurs respectively 14 times in Achor's talk, 28 in Gilbert's and 12 in Seligman's (not listed below because out of the top 10 occurrences), whereas it never occurs in Csikszentmihalyi's. Achor focuses on "brain" (22 occurrences) often linked to "positive" (15), though the expression "positive psychology" in its entirety occurs 4 times in Seligman's speech, twice in Achor's and never in the other two texts.

The conjunction "because" and the adverb "how" are typically used to explain the reason why something happens and to express in what manner, by what means and in what condition something happens, and this accounts for the prominence in usage in the texts sampled. Instead, it is worth-noting that "very" - a subjective adverb of quantity-occurs 15 times in Csikszentmihalyi's talk, somewhat strange because its indeterminacy might give the impression of being inappropriate or imprecise in strictly scientific terms. However, it is mainly used to express personal evaluations about personal aspect of his narrative, such as in I interviewed some of the CEOs who had been nominated by their peers as being both very successful and very ethical, very socially responsible or in this $[\ldots]$ process $[\ldots]$ can only happen to someone who is very well trained. So, the adverb "very" is never used to describe scientific data.

As regards the use of technical words, "flow" is the only one on the table below, used 14 times by Csikszentmihalyi. The term, was coined by the scholar himself in 1975 to describe "the holistic experience that people feel when they act with total involvement" (Csikszentmihalyi, 1975, p. 36). The speaker explains the word through the metaphor "as opening a door that floats in the sky" and the analogy of this "optimal experience" to the way Albert Einstein described how he imagined the forces of relativity, when he was struggling with trying to understand how it worked. The same word is mentioned by Seligman too, 7 times in his speech just because he makes reference to Csikszentmihalyi as a co-founder of positive psychology, and also to remark the difference between happiness and flow, regarded as two different states of mind.

Table 6. Word frequency: top 10 occurrences

\begin{tabular}{llll}
\hline $\begin{array}{l}\text { The happy secret to } \\
\text { better work }\end{array}$ & $\begin{array}{l}\text { The surprising science of } \\
\text { happiness }\end{array}$ & Flow, the secret to happiness & $\begin{array}{l}\text { The new era of positive } \\
\text { psychology }\end{array}$ \\
\hline brain 22 & happiness 28 & people 18 & life 41 \\
positive 15 & like 21 & very 15 & people 26 \\
because 14 & because 21 & how 14 & positive 26 \\
how 14 & people 16 & feel 14 & psychology 20 \\
happiness 14 & two 15 & flow 14 & good 20 \\
just 12 & really 15 & life 11 & emotion 16 \\
up 10 & us 15 & experience 10 & time 14 \\
get 10 & make 15 & doing 10 & len 14 \\
average 10 & right 14 & because 8 & how 13 \\
two 9 & just 13 & go 8 & three 13 \\
\hline
\end{tabular}

\subsection{Non-Verbal Elements of the Talk}

Table 7 illustrates some data about the non-verbal elements of the presentations, which can be regarded as key ingredients to a successful speech delivery. One of them is humour, typically used to keep the audience's interest alive and create rapport with them (Scotto di Carlo, 2014b) and as a consequence something that cannot be overlooked. Humour is a distinctive feature of Achor's style, since laughter arises every 52 seconds (14 times) in his talk, though Gilbert also resorts to this device (10 times). Seligman leads the public to hilarity (6 times) in the first part of his speech when he tells a personal anecdote about his past attempt at explaining what positive psychology is to the $\mathrm{BBC}$, and his inability to meet their requests in a short TV sound bite time frame. Humour is not used by Csikszentmihalyi for whom laughter is registered only once.

Applause witnesses a positive feedback too, but despite the fact that all the presenters are applauded at the end of their talk, Achor is the only one who receives one in the course of his performance which is not so usual at a TED event. This may find an explanation in the fact that perhaps the public prefers not to interrupt the speaker's flow of ideas while he/she is delivering the speech, but since in the case of Achor, hilarity seems to be a prominent strategy to grab the public's attention, he cannot but be applauded.

As regards the presence of question marks, they provide a decisive clue to the unravelling of how much the presenter tries and involve the audience. Through questions he/she gives the spectators the time to understand a point and reflect on it, and feel personally engaged in the talk. In this case Gilbert makes wide use of questions, going well beyond the others (40). He establishes rapport with the public just saying things like And this is exactly 
what you expected, isn't it? or ...it has no impact whatsoever on your happiness. Why? Because happiness can be synthesized. Seligman's questions are 19, though 7 are used to narrate an anecdote involving questions. Achor uses 8 interrogative forms, mostly to interact with the public, such as in Why are some of you high above the curve in terms of intellectual, athletic, musical ability, creativity, energy levels, resiliency in the face of challenge, sense of humor? Whereas Csikszentmihalyi resorts to questions only once.

The other two elements I took into consideration are purely informative and supportive to the previous items, thus no numeric data are made available: story-telling and visual aids. The former-meant as a wide narrative genre (fairy tales, fables, anecdotes) - allows the speaker to help the audience understand complex concepts and also send a message (Parkin, 2010) and that is why stories represent such an important device in presentations. The use of narrative has become a credible and even fashionable device in training as well as in processes aimed at facilitating change (ibid., p. 1) and that is what TED is for. The tale is a metaphorical game and the metaphor allows the listener to observe the same phenomenon from a different point of view, and then to see new solutions. The conductor using appropriate metaphors can create the conditions for an epistemological change that may start from the cognitive and emotional development perceived (Casula, 1997, p. 76). Achor widely focuses on story-telling to grab his public's attention and keep it alive and most of the stories and examples he chooses are personal and amusing. The same technique appears in Gilbert's and Csikszentmihalyi's talks but stories are mainly related to scientific experiments and research, often used to reinforce a concept or an idea.

Visual aids are used by all the four presenters but while Achor mainly shows images of places or some short lists of words, Gilbert and Csikszentmihalyi illustrate data and charts and Seligman lists words and definitions to make the public understand the point and some fundamental tenets of psychology.

Table 7. Other element (mainly non-verbals)

\begin{tabular}{|c|c|c|c|c|}
\hline Items/Talks & $\begin{array}{l}\text { The happy secret to } \\
\text { better work }\end{array}$ & $\begin{array}{l}\text { The surprising science } \\
\text { of happiness }\end{array}$ & $\begin{array}{l}\text { Flow, the secret to } \\
\text { happiness }\end{array}$ & $\begin{array}{l}\text { The new era of positive } \\
\text { psychology }\end{array}$ \\
\hline Laughter & 14 & 10 & 1 & 6 \\
\hline Applause & 2 & 1 & 1 & 1 \\
\hline Question marks & 8 & 40 & 1 & 19 \\
\hline Story-telling & Yes (wide and personal) & $\begin{array}{l}\text { Yes (mainly from } \\
\text { scientific experiments) }\end{array}$ & $\begin{array}{l}\text { Yes (personal introduction } \\
\text { and scientific experiments) }\end{array}$ & Yes (wide and personal) \\
\hline Visual aids & $\begin{array}{l}\text { Yes (mainly to show } \\
\text { pictures) }\end{array}$ & $\begin{array}{l}\text { Yes (mainly to show } \\
\text { data) }\end{array}$ & Yes (mainly to show data) & $\begin{array}{l}\text { Yes (mainly to list useful } \\
\text { elements for the public) }\end{array}$ \\
\hline
\end{tabular}

\section{Conclusions}

Therefore, on the basis of my analysis related to how PP has been dealt with by scholars in TED talks, and more generally how scientific dissemination can be been carried out to lay people outside of academic contexts, I can draw some conclusions. First of all, it can be confirmed that TED Talks do not seem to show the typical features of conventional scientific dissemination, i.e. specialized discourse (academic discourse and what it entails in terms of register, technical vocabulary, etc.) nor a tendency towards understatement. Presenters adapt themselves to the context (live participants, online participants, entertainment, spreading of ideas,...), so TED really breaks with an 'old' consolidated formal representation of science and manifests itself as a new hybrid genre(Note 16). Presenters may go from a more scientific-like approach to knowledge-dissemination (never taken to extremes) to a very informal one (sometimes taken to extremes). It mirrors other media (TV, radio) and programmes (shows or comedies) reminding us that the E in the acronym TED stands for "entertainment"; this is why style may seem to prevail over content—how you say it, rather than what you say; thus, augmenting its comprehensibility.

With regard to scientific vocabulary what stands out is its limited use, always defined or introduced by examples, stories and metaphors to create a vivid image in the audience. The scientist adapts him/herself to the public in order to establish rapport and credibility. TED Talks seem to be the symbol of a new globalised society, hyperactive or only dynamic, that often connects learning and entertainment and gives knowledge a ready-to-use and even practical purpose. 


\section{References}

Achor, S. (2011). The happy secret to better work. Retrieved from https://www.ted.com/talks/shawn_achor_the_happy_secret_to_better_work

Bratton, B. (2013). We need to talk about TED. Retrieved from http://www.theguardian.com/commentisfree/2013/dec/30/we-need-to-talk-about-ted

Caliendo, G. (2012). The popularisation of science in web-based genres. In G. Caliendo \& G. Bongo (Eds.), The Language of Popularisation: Theoretical and Descriptive Models (pp. 101-132).

Caliendo, G., \& Compagnone, G. (2014). The popularisation of science in web-based genres. Lingue e Linguaggi, $11,105-122$.

Casula, C. (1997). I porcospini di Schopenhauer: Come progettare e condurre un gruppo di formazione di adulti. Milano: Franco Angeli.

Cialdini, R. (2007). The Psychology of Persuasion. New York: Harper Collins.

Cloître, M., \& Shinn, T. (1985). Expository practice: Social, cognitive and epistemological linkages. In T. Shinn and R. Whitley (Eds.), Expository science: forms and functions of popularisation (pp. 31-60). Dordrecht, D. Reidel Publishing. https://doi.org/10.1007/978-94-009-5239-3_2

Compagnone, A. (2017). The Reconceptualization of Academic Discourse as a Professional Practice in the Digital Age: A Critical Genre Analysis of TED Talks. Journal of Language and Communication in Business, 27(54), 49-69. https://doi.org/10.7146/hjlcb.v27i54.22947

Compagnone, G. (2015). The popularisation of science in web-based genres. Journal of Language and Communication in Business, 54, 49-69. https://doi.org/10.7146/hjlcb.v27i54.22947

Coopman, S., \& Lull, J. (2012). Public Speaking: The Evolving Art. Boston, MA: Wadsworth Cengage Learning. Csikszentmihalyi, M. (1975). Beyond Boredom and Anxiety. Jossey-Bass: San Francisco, CA.

Csikszentmihalyi, M. (2004). Flow, the secret to happiness. Retrieved from https://www.ted.com/talks/mihaly_csikszentmihalyi_on_flow

D’Avanzo, S. (2015). Speaker Identity vs. Speaker Diversity: The Case of TED Talks Corpus. In G. Balirano \& M. C. Nisco (Eds.) Languaging Diversity: Identities, Genres, Discourses (pp. 279-297). Newcastle upon Tyne: Cambridge Scholars.

Edmund, N. W. (2005). End the Biggest Educational and Intellectual Blunder in History. Fort Lauderdale: Scientific Method Publishing.

Fahnestock, J. (1986). Accommodating Science: The Rhetorical Life of Scientific Facts. Written Communication, 3(3), 275-296. https://doi.org/10.1177/0741088386003003001

Gallo, C. (2014). Talk like TED: The 9 Public Speaking Secrets of the World's Top Minds. New York, NY: St. Martin's Press.

Gass, R. H., \& Seiter, J. S. (2015). Persuasion: Social influence and compliance gaining. London and New York: Routledge. https://doi.org/10.4324/9781315664194

Gilbert, D. (2004). The surprising science of happiness. Retrieved from https://www.ted.com/talks/dan_gilbert_asks_why_are_we_happy

Gregory, T. (2010). Dictionary of Rhetorical Terms. Bloomington, IN: Xlibris.

Heller, N. (2012). Five Key TED Talks. Retrieved from http://www.newyorker.com/culture/culture-desk/five-key-ted-talks

Ludewig, J. (2017). TED Talks as an Emergent Genre. CLCWeb: Comparative Literature and Culture, 19(1). https://doi.org/10.7771/1481-4374.2946

Masi, S. (2016). Gestures in Motion in TED Talks: Towards Multimodal Literacy. In V. Bonsignori \& B. Crawford Camiciottoli (Eds.), Multimodality across Communicative Settings, Discourse Domains and Genres (pp. 146-165).

McCroskey, J. (1970). Measures of communication-bound anxiety. Speech Monographs, 37, 269-277. https://doi.org/10.1080/03637757009375677

McCroskey, J. C. (1977). Oral communication apprehension: A summary of recent theory and research. Human 
Communication Research, 4, 78-96. https://doi.org/10.1111/j.1468-2958.1977.tb00599.x

McCroskey, J. C. (1984), An introduction to rhetorical communication (4th ed.). Englewood Cliffs, NJ: Prentice Hall.

Paltridge, B. (2006). Discourse Analysis. An Introduction. London/New York: Continuum.

Parkin, M. (2010). Tales for trainers: Using stories and metaphors to facilitate learning. London: Kogan Page.

Peterson, C. (2006). A primer in positive psychology. New York: Oxford University Press.

Rasulo M. (2015). TED Culture and Ideas Worth Sharing. In G. Balirano \& M. C. Nisco (Eds.), Languaging Diversity: Identities, Genres, Discourses (pp. 262-278). Newcastle upon Tyne: Cambridge Scholars.

Robbins, M. (2012). The trouble with TED talks. Retrieved June 12, 2016, from http://www.newstatesman.com/martin-robbins/2012/09/trouble-ted-talks

Sager, J. C., Dungworth, D., \& McDonald, P. F. (1980). English Special Languages. Wiesbaden: Brandstetter.

Scotto di Carlo, G. (2014). New trends in knowledge dissemination: TED Talks. Acta Scientiarum. Language and Culture, 36(2), 121-130. https://doi.org/10.4025/actascilangcult.v36i2.22619

Scotto di Carlo, G. (2014a). Figurative Language in Science Popularisation: Similes as an Explanatory Strategy in TED Talks. 3L: The Southeast Asian Journal of English Language Studies, 20(3), 1-16. https://doi.org/10.17576/3L-2014-2003-01

Scotto di Carlo, G. (2014b). Humour in popularisation: Analysis of humour-related laughter in TED talks. European Journal of Humour Research, 1(4), 81-93. https://doi.org/10.7592/EJHR2013.1.4.scottodicarlo

Scotto di Carlo, G. (2014c). The Role of Proximity in Online Popularizations: The Case of TED Talks. Discourse Studies, 16(4), 591-606. https://doi.org/10.1177/1461445614538565

Seligman, M. E. P. (2002). Authentic happiness: Using the new positive psychology to realize your potential for lasting fulfillment. New York: Free Press.

Seligman, M. E. P. (2004). The new era of positive psychology. Retrieved from https://www.ted.com/talks/martin_seligman_on_the_state_of_psychology

Seligman, M. E. P., \& Csikszentmihalyi, M. (2000). Positive psychology: An Introduction. American Psychologist, 55, 5-14. https://doi.org/10.1037//0003-066X.55.1.5

Simons, H. W. (2001). Persuasion in society. Thousand Oaks, CA: Sage

Takaesu, A. (2013). TED Talks as an Extensive Listening Resource for EAP Students. Language Education in Asia, 4(2), 150-162. https://doi.org/10.5746/LEiA/13/V4/I2/A05/Takaesu

Ure, J. (1971). Lexical density and register differentiation. In G. Perren \& J. L. M. Trim (eds), Applications of Linguistics (pp. 443-452). London: Cambridge University Press.

\section{Notes}

1) https://www.ted.com/about/our-organization

2) In Achor's website the home page presents the slogan "Happiness is the joy you feel moving towards your potential" and courses are offered to the visitor in order to improve skills in the field. http://www.shawnachor.com/

3) As the site shows this is the motto of TED: https://www.ted.com/\#/

4) https://www.ted.com/about/our-organization/history-of-ted

5) https://www.ted.com/about/programs-initiatives/ted-prize

6) https://tedxesl.com/

7) Cf. Carnagey D. (later Carnegie) and J. B. Esenwein (1915), The Art of Public Speaking, Springfield, MA: The Home Correspondence School.

8) https://www.ted.com/about/our-organization [Accessed 18th September 2018].

9) http://behavioralscientist.org/love-ted/ [Accessed 18th September 2018].

10) Cf. Andrews J. (2014), Ted Talk Secrets: Storytelling and Presentation Design for Delivering Great Ted Style Talks 
11) https://thenewinquiry.com/against-ted/ [Accessed 24th September 2018]

12) The number of viewers has been updated as of 18 February 2019.

13) Based on an average speaking speed of 180 words per minute (www.wordcounter.net)

14) The value of lexical density does not usually exceeds $40 \%$ in oral texts because speech tends to be more unsophisticated, non-academic, and time pressures of speaking increase and result in texts being lexically simpler (Ure, 1971).

15) This scale assigns from 6 (easy) to 20 (hard) based on the years of formal education needed to understand a text.

16) Cf. p.1

\section{Copyrights}

Copyright for this article is retained by the author, with first publication rights granted to the journal.

This is an open-access article distributed under the terms and conditions of the Creative Commons Attribution license (http://creativecommons.org/licenses/by/4.0/). 